\title{
SPEECH ACTS AND SUB-SENTENTIAL SPEECH
}

\author{
J. ROBERT THOMPSON \\ Department of Philosophy and Religion \\ Mississippi State University \\ jrt260@msstate.edu
}

SUMMARY: In this paper, I compile some reasons for resisting Stainton's (2006) analysis of sub-sentential speech. My resistance stems from considerations about the intentions and expectations of those who communicate using sub-sentential speech. I challenge Stainton's reasons for thinking that some sub-sentential utterances have the status of full-fledged speech acts and argue that they turn out to be degenerate speech acts. After offering my own analysis of sub-sentential speech, I recommend that by revisiting the divide and conquer strategy Stainton dismisses for handling the alleged cases of genuine sub-sentential speech, we can resist radical forms of contextualism suggested by his analysis.

KEY WORDS: assertion, contextualism, ellipsis, sub-sentences

RESUMEN: En este texto recopilo algunas razones para oponerse al análisis del habla suboracional que plantea Stainton (2006). Mi oposición surge de consideraciones en torno a las intenciones y expectativas de quienes se comunican usando el habla suboracional. Pongo en duda las razones que aduce Stainton para pensar que algunas proferencias suboracionales tienen el estatus de actos de habla en toda la extensión de la palabra y arguyo que resultan ser actos de habla degenerados. Después de ofrecer mi propio análisis del habla suboracional, recomiendo que, retomando la estrategia "divide y vencerás" que Stainton descarta para manejar los presuntos casos de habla suboracional genuina, podemos oponernos a las formas radicales de contextualismo que su análisis sugiere.

PALABRAS CLAVE: aseveración, contextualismo, elipsis, suboraciones

\section{Introduction}

Robert J. Stainton's Words and Thoughts: Subsentences, Ellipsis and the Philosophy of Language (hereafter WT) is both an impressive defense of the fact that some instances of sub-sentential speech qualify as genuine speech acts, and a development of the implications that would seem to follow from this fact. His work forces us to question the role of natural language sentences both in linguistic processing and in thought in general. If Stainton is correct, not only will appeals to natural language sentences fail to be mandatory in many explanations of the relationship between language and thought, but such appeals obscure the phenomena being explained.

In this paper, I compile some reasons for resisting Stainton's analysis of sub-sentential speech. My resistance is not rooted in the considerations Stainton offers (e.g. worries about the context principle 
or the fact that sub-sentences couldn't be premises in an argument), but rather stems from considerations about the intentions and expectations of those who communicate using sub-sentential speech. I challenge Stainton's reasons for thinking that some sub-sentential utterances have the status of full-fledged speech acts and argue that they turn out to be degenerate speech acts. After offering my own analysis of what can be achieved by sub-sentential speech, I recommend that we revisit the divide and conquer strategy Stainton dismisses for handling the alleged cases of genuine sub-sentential speech. Though I can offer nothing like the chapters of detailed and sustained arguments in WT, I hope to suggest that when examining the examples of sub-sentential speech, most sub-sentential utterances will be seen as degenerate speech acts, and the ones that seem least degenerate are actually excellent candidates for being treated as cases of syntactic ellipsis. I am not sure if my analysis will handle every case of sub-sentential speech, but I think it offers a new strategy for how to deal with this phenomenon, and hence a way of avoiding some of the radical implications for the semantic-pragmatic distinction that would arise if Stainton is correct about sub-sentential speech.

\section{Setting the Stage: Why All the Fuss over Sub-Sentential Speech?}

\subsection{The Phenomenon}

The phenomenon of sub-sentential speech - the uttering of words and phrases in isolation, i.e. not in the context of a sentence- dominates WT. Stainton summarizes the point of WT with the following argument schema:

Premise 1: Speakers genuinely can utter ordinary words and phrases in isolation, and thereby perform full-fledged speech acts.

Premise 2: If speakers genuinely can utter ordinary words and phrases in isolation, and thereby perform full-fledged speech acts, then suchand-such implications obtain.

Conclusion: Such-and-such implications obtain. (WT, p. 3)

Whereas many theorists deny that words and phrases can be uttered in isolation (and thereby perform full-fledged speech acts) Stainton insists that they are in fact uttered in isolation all the time (and often perform full-fledged speech acts). Hence, much of the book is a 
sustained examination of various attempts to undercut the legitimacy of this use of words and phrases in isolation.

Stainton offers a wide variety of sub-sentences in order to stress their heterogeneity as a class, including, inter alia, prepositional phrases, quantificational noun phrases, verb phrases, proper nouns, and definite descriptions. He hopes to show that many examples of these sorts of sub-sentences can be uttered in isolation, and nevertheless communicate a proposition. To use a favorite example from WT, Sanjay and Silvia are loading a moving van and Silvia is searching for a missing table leg. Sanjay utters the mere phrase

(1) On the stoop

and by so doing, according to Stainton, communicates the singular de re proposition that that leg is on the stoop.

To many, this example may not sound at all controversial, but Stainton goes to great lengths to explain exactly what he thinks is going on here and why his claim is taken to be controversial by so many theorists. Specifically, he wants to insist that there is not a natural language sentence present in this communicative exchange; not one somehow covertly present (e.g. unpronounced), not one produced in the mind of Sanjay, and not one recovered by Silvia. Moreover, what happens as a result of the utterance of this isolated sub-sentence is not that a fully propositional content is merely communicated, conveyed, implicated, or suggested - it is asserted. Much of WT, then, is dedicated to establishing the legitimacy of sub-sentential speech by arguing for two main claims: some examples of sub-sentential speech are full-fledged speech acts, a genuine assertion, command, question, etc.; and these sub-sentential utterances really are $s u b$-sentential i.e. they are not actually sentential in some way or other.

\subsection{The Fuss}

It is important to note, as Stainton often does, that although subsentential speech is an interesting phenomenon for linguists and philosophers to study in its own right, the sorts of implications that seem to hold if it is found to be legitimate (the "such-and-such implications" of the argument above) are critical for several debates about the nature of language and thought. In this paper, I will be concerned primarily with the positive proposal Stainton offers in Chapter Eight and the debate discussed in Chapter Eleven regarding the boundary between semantics and pragmatics. The distinction between semantics and pragmatics is in an especially intense degree 
of flux these days, and I think that if Stainton is (mostly) right about sub-sentences, this is extremely good support for a certain perspective on the relationship between semantics and pragmatics -Relevance Theory. ${ }^{l}$ Since I think there are serious problems for that perspective, I hope to cast some doubt on whether Stainton is right about sub-sentences.

My worries stem from the puzzle Stainton raises at the end of chapter three. He acknowledges that when considering sentences, we find it natural to distinguish between the content that is asserted and the content that is merely pragmatically conveyed. He describes the traditional account of how the asserted content is determined, "The content asserted, put roughly, is the context-invariant semantics of the sentence, plus the content contributed by context to elements of the sentence's structure" (WT, p. 59). ${ }^{2}$ Though many theorists disagree as to how context interacts with the sentence structure, Stainton notes that these theorists still agree

that there is a content-bearing structure provided by the expression used, and that what is asserted is the content of what one gets by developing that structure. It is precisely the latter that affords the natural divide: what is merely pragmatically conveyed is content that doesn't result merely from development of the structure used. (WT, p. 59)

But, here is the puzzle Stainton acknowledges arises if sub-sentential speech is genuine: When it comes to sub-sentences, "the content of the assertion cannot be got merely by modifying or shading the contents of the expression uttered. No matter how we develop the expression that was spoken, the result will still be sub-propositional..." (WT, p. 59). The result is that "when it comes to isolating what is genuinely asserted, we can no longer appeal to the difference between developing a given structure and bringing in a new structure entirely" (WT, p. 59). This result may not seem especially problematic - one need only find some other rule for including what is asserted and excluding what is merely conveyed. However, I will argue that coming up with such a rule can be difficult enough just for sentences, let alone for sub-sentences, given the perspective Stainton and the other Relevance Theorists take on the semantic-pragmatic divide.

${ }^{1}$ For systematic treatments of Relevance Theory, see Sperber and Wilson 1995, and Carston 2002.

${ }^{2}$ To match the terminology used in WT, I quote at length in laying out the puzzle. 
Herman Cappelen and Ernie Lepore (2005a, 2005b, 2007) have generated a series of well-known worries for theories that claim that what is asserted does not result merely from development of the sentence structure (a position I call moderate contextualism, which includes Stainton and the Relevance theorists). These theories argue for the existence of unarticulated constituents of what is said or asserted - elements that are found neither in the surface structure of the sentence that is uttered, nor in the logical form of that sentence. According to the moderate contextualists, in some cases these unarticulated constituents are needed for sentences to be able to express full propositions (and hence, in order for utterances of these sentences to assert full propositions), and in other cases are needed in order for a sentence to express the right proposition (and hence, in order for utterances of these sentences to assert the right proposition). What Cappelen and Lepore claim is that if the case can be made for such augmentation to account for what is asserted for a limited range of expressions, similar reasons will require us to augment almost all expressions in so many ways that we will be forced to become radical contextualists. As a result, we will ultimately be unable to rule out so much contextual influence that we will be incapable of drawing the distinction between what is asserted and what is conveyed, and will be forced eventually to deny the stability of context-invariant word and sentence meanings (so we will be forced to deny the existence of semantic content).

Cappelen and Lepore explain that, in arguing for the need for unarticulated constituents, moderate contextualists distinguish between sentences that are semantically complete and those that are semantically incomplete. For example, consider

(2) Steel isn't strong enough

The moderate contextualists argue that this sentence is missing something that must be supplied to express a full proposition - it is semantically incomplete because it does not specify the factor for which the steel is lacking sufficient strength. The sentence becomes semantically complete only when this factor is contextually supplied, as in

(3) Steel isn't strong enough to support the roof

Cappelen and Lepore, however, insist that moderate contextualists vastly underestimate the force of their arguments. They insist that an argument parallel to that which shows the incompleteness of 
(2) can be used to demonstrate the incompleteness of (3). They argue that, according to these contextualist considerations, still other factors would have to be taken into account in order to make the sentence semantically complete. However, once one starts examining the factors that could possibly be relevant, and hence be in need of completion in some context or other, where does one stop, i.e. when is the sentence finally semantically complete? Cappelen and Lepore specifically raise questions about the temporal factors that could be in need of completion (e.g. How long is the support supposed to last? Do a few seconds suffice? More than three days? Many years?), but insist that countless other factors that the contextualists have already generated in their own arguments cannot be ruled out without some sort of effective criterion - a criterion that will not be forthcoming.

Returning to Stainton's puzzle, the incompleteness of these sentences is reflected in determining what utterances of them can say or assert, as opposed to what they convey or communicate. As Kent Bach explains, "When a sentence is in this way semantically underdeterminate, understanding its utterance requires a process of completion to produce a full proposition" (Bach 1994, p. 125). In interpreting the utterance, the audience must add to the elements that are linguistically mandated by the syntax - the articulated constituentsand use pure pragmatics to generate what is missing - the unarticulated constituents - in order to generate the full proposition that was asserted by the speaker's utterance.

What Cappelen and Lepore show is that if we allow ourselves to be swayed by the moderate contextualists' arguments, there seem to be indefinitely many factors, i.e. indefinitely many possible unarticulated constituents of what is asserted by an utterance, that could be relevant, in some context or other. Hence, the contextualist arguments, even the more moderate versions, fail to recognize that, no matter how many context-dependent features are completed, there will always be others that could be relevant in some context, and hence stand in need of completion.

If there are unarticulated constituents that determine what is asserted, we need some principled manner of locating them so that we can say that these factors are relevant to what is asserted and contrast them against other factors that are relevant to meaning, yet are not part of what is asserted. If Cappelen and Lepore are right, the prospects of finding this principled manner are dim. I think this is a serious reason to worry about the moderate contextualist accounts of sentence interpretation, and a reason to resist those accounts, including Stainton's positive account and other Relevance Theoretic 
approaches. However, whether or not this applies to sentences is not crucial for the issue at hand. What should be clear is that even if this is not a serious worry about sentences, it is a monumental worry about $s u b$-sentences.

Stainton fully recognizes this worry and introduces the notion of a minimal proposition to solve the puzzle: whatever you need to fill in to get to a proposition is what is asserted; whatever goes beyond that is merely conveyed. ${ }^{3}$ But: which proposition? It looks as though on a particular communicative occasion there is an almost unbounded number of propositions floating around - some minimal, some not so minimal - that are reasonable candidates for what is asserted. Crucially, Cappelen and Lepore's worries are much more significant when there is less syntactic structure to operate upon, as is the case with sub-sentences. This is what is so problematic with sub-sentences: There is no obvious way of showing what their completeness should look like.

These are the motivations for my reactions to Stainton's proposal. If what he says about sub-sentential speech is true, then I don't think we can draw a distinction between what is asserted and what is conveyed, and the resulting theory of pragmatics lacks a notion of stable context-invariant word and sentence meanings. This leads to a conception of language where meanings are non-compositional; and languages like that, as the tradition goes, are not learnable. ${ }^{4}$ Since I find this conception of language unacceptable, I will attempt to show that Stainton is not right about sub-sentential speech. In the next two sections, I offer an alternative treatment of sub-sentential speech, and with it, a way of avoiding this slide towards radical contextualism.

\section{A Full-Fledged Speech Act?}

I want to examine whether Stainton has made his case that subsentences can be used to make full-fledged speech acts — specifically

\footnotetext{
${ }^{3}$ More precisely, Stainton says: "To my mind, what is asserted when a subsentence is used communicatively is that proposition which results from minimally adding to the content of the bare phrase actually uttered so as to arrive at a proposition. Non-asserted content, in contrast, is inferentially arrived-at content which goes beyond the minimal proposition, such that the addition is forced not by the sub-propositional nature of the thing uttered, but solely by the conversational inadequacies of the propositional result" (WT, p. 60).

${ }^{4} \mathrm{I}$ do not attempt to defend or develop these claims here - they are well-known from the classic arguments of Donald Davidson (1984), and, more recently, Jerry Fodor and Ernie Lepore (2002).
} 
the claim that they can be used to make full-fledged assertions, questions, commands, etc. Stainton specifies four requirements for fullfledged speech acts: (i) that the action have the form of a "genuine linguistic act", (ii) that the content be propositional, (iii) that the speaking event exhibit illocutionary force, and (iv) that the content be "literal", i.e. asserted, asked, etc., and not merely conveyed (WT, p. 49). The first is intended to rule out non-linguistic items like gestures or pictures, and requires that the act will have semantic and syntactic properties, in addition to exhibiting full grammaticality. The second requires at a minimum that the content is not overly vague and that it should not be paraphrased by phrases that are semantically distinct in some radical way. The third notes that real speech acts must have some level of specificity and determinacy in regard to their force-bearing features - a level of specificity and determinacy lacking from other communicative acts such as a kick under the table or a smirk. The fourth specifies that the proposition is not merely suggested or conversationally implicated.

Given these requirements, I believe that one crucial question confronts us about the available options: Do these sub-sentential utterances really assert determinate propositions, or do they communicate propositions in some other way? I will argue that by offering the following sort of analysis, the structure of many of Stainton's arguments makes the first option look much more palatable than it is because he underestimates the frameworks available within the second option:

Put another way, you might be able to convince yourself that some of the examples I've given lack a fully determinate force or propositional content, hence the original $\mathrm{P} 2^{5}$ really does have some bite; but, not to put too fine a point on it, it is downright preposterous to suppose that such utterances are not contentful or force-bearing at all - to suppose that, content-wise and force-wise, the communicative acts at play are more akin to a kick under the table than to an utterance of a complete sentence. (WT, p. 148)

I do not deny that sub-sentences can be used to communicate in a way that nudges, winks, and kicks under the table cannot; but this does not entail that they can, for example, be used to assert a proposition - they are too incomplete for that. But, they can be used to suggest or convey a range of propositions. This sort of speech

\footnotetext{
${ }^{5}$ Stainton is referring to Jason Stanley's (2000) P2 from his Divide and Conquer Strategy: If a putative sub-sentential utterance $u$ lacks a determinate propositional content and force, then $u$ is not a full-fledged speech act exhibiting truth-conditions.
} 
occurs all the time, but it is not full-fledged in the way the conditions require, i.e. sub-sentential utterances are degenerate speech acts. My claim is that as we allow ourselves to see the second option as more viable, we will be less likely to think of uses of sub-sentences as really asserting determinate propositions. Asserting a determinate proposition is a special sort of thing, and only an utterance with a certain type of structure can accomplish it.

Here is my plan: I want to concede that the examples of subsentential speech under discussion satisfy (i), then explore (ii) in such a way that we will need to reconsider whether (iii) and (iv) are satisfied by uses of sub-sentences in the right sort of way. What I want to stress is that the sub-sentential utterances that are truly subsentential are the wrong sort of item to assert, ask, and order. They are inhibited by their incomplete syntactic structure, which limits the materials that are available for the speaker to expect the hearer to be able to develop into a determinate proposition.

\subsection{Examining the Conditions}

Condition (II): Stainton addresses (ii) to refute the claim that the uses of sub-sentences under question are not expressing something fully propositional. To accomplish this, he considers the following argument from Jason Stanley (2000):

(P1) A full-fledged speech act must involve a fully determinate proposition.

(P2) The contested cases don't involve a fully determinate proposition.

C: The contested cases are not full-fledged speech acts. (WT, p. 52)

Stainton initially denies (P1), balking at the idea that to be a fullfledged speech act, a determinate proposition must be involved. Instead, he offers an alternative notion of propositional that requires merely that the content be "message-like" (WT, p. 52). He advocates this alternative notion by showing that plenty of vague sentential speech would not count as full-fledged because it also fails to express a determinate proposition. As Stainton explains, in many such cases, we just don't ask for hyper-specificity and don't expect someone who utters "I loved it" after exiting a roller coaster to 
be able to say, to the exclusion of all truth-conditionally distinct alternatives, precisely what she meant by "it". (The act of riding? The whole experience, from waiting in line to walking down the exit ramp? The roller coaster itself? The feelings she experienced while riding? Which such feelings?) Nor need she have a clear idea of just what unique sense of "love" was intended. (WT, p. 53)

This may be true, but I fail to see how it casts doubt upon whether the condition is required to be a proper speech act. After all, what sorts of speech would we be excluding from being full-fledged by maintaining it as a requirement? This speech would have some propositional, but merely message-like content, and would not be fully determinate. It is unclear just how imprecise the message can be and still be propositional - Stainton does not say - but, we at least are told that it needn't be as precise, generally, as the quoted aspects above about the girl and the ride. However, it is not obvious that being more inclusive about speech acts helps Stainton's case. It makes more sub-sentential (and sentential) speech count as propositional, but keep in mind that according to Stainton, these propositions must be part of what the use of a sub-sentence (or sentence) asserts, not merely what it communicates. He can surely get us to agree that plenty of speech can be propositional enough - that a vague message about some event is getting across to the audience without being overly determinate - but in these cases the messages are going to fail to count as what the utterances assert.

By whatever standards of determinacy he selects, there will be a set of utterances for which what they express is either determinate enough or not to count as what was asserted (this goes for sentences and sub-sentences). All that (P1) says is that any utterance that isn't propositional to this extent is degenerate. So, it looks like the only criticism Stainton makes against $(\mathrm{P} 1)$ is that it excludes sentential and sub-sentential utterances that lack an asserted content that is determinate to this extent from being full-fledged speech acts. But what is the problem with doing that? An utterance should be considered seriously degenerate if we could not even locate what it asserted to this extent.

So, the mere fact that the standards for full-fledged speech acts exclude some uses of sentences isn't reason enough to reject them, since some uses of sentences shouldn't count as full-fledged either. We require a certain level of precision in what is asserted, and sentences or sub-sentences can either be used to assert propositions like that or they can't. Stainton actually recognizes this when he moves on 
to (conditionally) concede (P1), and then challenges (P2) by showing that some sub-sentential speech actually meets even the unreasonably high standards of determinacy involved in (P1). He considers two ways of demonstrating the presence of something fully propositional - one that tries to infer that something fully propositional was meant/asserted merely because there was something fully propositional in the vicinity of the linguistic exchange, and one that tries to infer the existence of something fully propositional from the presence of an act of successful communication. He stresses that these are inadequate for demonstrating the legitimacy of sub-sentential speech precisely because neither locates the proposition in the role that is crucial for Stainton: what is asserted or meant by an utterance.

Stainton needs to avoid a dilemma. The vaguer he allows the proposition to be, the less clear it is that the proposition is being asserted rather than communicated. The more precise it becomes, the less clear it is that there isn't actually a sentential structure involved in the ways that Stainton forbids. To deny (P2), he needs to show that there are some uses of sub-sentences that have contents propositional enough to be capable of asserting, and he needs to show that when they are determinate enough, that they are actually being asserted and not merely conveyed. If we find that there are no such uses of sub-sentences, then we need not relegate them to the status of winks and nudges, but we can still have reasons to describe them as degenerate speech acts. ${ }^{6}$

Condition (III): Stainton next considers (iii) and the challenge that the examples of sub-sentential speech under discussion are not forcebearing in the relevant sense. Stainton summarizes this challenge as follows:

(P1) A full-fledged speech act must involve a determinate, specific, illocutionary force.

(P2) The contested cases don't involve a determinate, specific, illocutionary force.

C: The contested cases are not full-fledged speech acts.

Much like his strategy regarding (ii), Stainton tries to show that (P1) is too high a requirement for many cases of sentential speech to meet. He notices that certain sentential utterances, such as "You

${ }^{6}$ The issue of whether there are any sub-sentences that actually $d o$ meet conditions (ii)-(iv) will be addressed at the end of this section. 
must turn in your final report before you leave in the afternoon", as uttered by Maria to Susan, may fail to have a determinate, specific, illocutionary force, e.g. among an assertion of policy, a request, or an order (WT, p. 56). Stainton then asks

\begin{abstract}
Would it follow that Maria, in so speaking, did not perform a genuine speech act, but only did something less than "full-fledged"? Can we, on these grounds alone, really assimilate her utterance of [that sentence] to things like kicks under the table, grunts, smirks, etc. —which is what my opponents here wish to do with sub-sentence uses? Surely not. (WT, p. 57)
\end{abstract}

Here we have the same sort of move as we received regarding (ii) and we need to raise the same sort of questions as before. What are the consequences of not counting (as full-fledged speech acts) examples where there are multiple possible forces involved? He explains that many of these cases are "perfectly fine speech act[s]" (WT, p. 57) because they have the possibility of being satisfied or not, as in the suggestion that Maria will be unsatisfied if the report is not turned in by the time Susan leaves. But this only tells us that the utterance could have successfully gotten a message across. Stainton himself insists that he wants and needs sub-sentential speech to do more than just get a message across — not every linguistic act that gets a message across should count as a full-fledged speech act. He wants them to have real force. Stainton suggests that if we deny that this is a full-fledged speech act, we are relegating it to a wink or nudge, but we need not, nor should not, do such a thing.

One way to see the degenerate nature of this speech act is to examine more closely the expectations that would hold between the speaker and the audience - to consider reactions that Susan could have or that Maria could expect her to exhibit, and whether these reactions and expectations would be justified, given the nature of what was uttered in this context. Keeping in mind the burdens placed upon the audience, we can show the sort of limitations involved in an utterance with a less than determinate or specific force. By uttering a sentence without a precise force, Maria has no reason to be terribly upset if Susan doesn't turn in the report that day, had Susan judged the utterance to be a polite request and not an order. By choosing that particular sentence rather than another one with a more determinate force, Maria should be willing to shoulder a greater share of the communicative blame if the desired outcome is not reached. Even if the desired outcome was reached, we can identify 
the risks involved in using utterances like these with indeterminate force, noting their expected limitations; we can outline the numerous ways the audience could achieve illocutionary uptake and question whether the speaker should find any of these ways of divining the force to be more or less probable, given that utterance in that context. So, we have good reasons to judge these sorts of cases as degenerate when compared to ones where the determinate force avoids these risks, especially if the speaker had a particular perlocutionary effect in mind that she wanted to achieve. If she wanted this accomplished, why would she utter that sentence?

When it comes to sub-sentences, the lack of additional linguistic material may make it even more difficult for speakers and hearers to have reasonable expectations about the outcomes resulting from the act. If adding words or phrases, or making something fully sentential, is a typical way of eliminating these indeterminacies of force, then the defender of sub-sentential speech cannot ignore this fact and say that in general, there is nothing wrong with multiple forces because some uses of sentences can have multiple forces and nevertheless communicate successfully. As with (ii), that is not what's at issue.

Maria could have uttered the sub-sentence "Before you leave in the afternoon". But, in this case she has even less justification for being upset with Susan if she fails to deliver the report by the end of the day. In addition to confusion over the force of the utterance, we could imagine confusion over whether Maria wanted the report, or for her to stop by and talk about the report, or stop by and talk about her pending promotion. As an act, it is not as bad off as what would happen if Maria stuck her head in Susan's office and winked, but it is not able to add burdens upon Susan regarding the fact that the report was the object of interest. If Stainton is right, the context may be able to get the additional material into Susan's mind without the presence of more linguistic material, but even then, the sub-sentential utterance is degenerate to at least the same degree as the sentential one. Neither the sentence nor the sub-sentence speech is as bad off as the wink, but both the linguistic examples are degenerate nevertheless. Stainton needs to show us examples where uses of sub-sentences are not degenerate in this way.

Condition (IV): Stainton gives two reasons for thinking that subsentences can be used to literally assert, and not merely convey, propositions. First, he notes that if sub-sentential speech happened to be more like non-literal, metaphorical speech, or more like working out conversational implicatures, the audience would notice this 
phenomenologically. However, he claims that hearers do not react to sub-sentential speech in the same way they do when confronted with actual non-literal speech. Second, he notes that in order to settle this issue, we need to get clearer about why it matters whether something is a real assertion or not. Here he suggests that we need to look more carefully into the practical consequences of assertion, i.e. the things we hold people accountable for based on their linguistic behavior. If there are legal, moral, and communicative burdens and obligations placed on those folks who assert, as opposed to some other linguistic behavior, then we can ask whether some sub-sentential speech can also warrant these burdens as well. For example, Stainton notes that genuine assertions can be used to lie, and not merely mislead, and then offers an example where a sub-sentence is used to lie. Hence, he claims that by both of these standards sub-sentential speech can genuinely assert (and command and question).

In response, I do not share Stainton's view that communicating with sub-sentences is phenomenologically dissimilar from working out conversational implicatures or metaphors. To show this, I will concentrate on the interpretation of commands and questions and suggest an account where the alleged cases of sub-sentential assertion are more like commands and questions than Stainton claims. In doing this, the notion that communicators don't react differently to the use of sub-sentences than to the use of sentences will lose much of its punch.

Stainton's best cases - those where it looks as if sub-sentences are perhaps being used to assert - are cases where there is an object being talked about which is in (potentially) full view of the interlocutors. "From Columbia" with a bag of coffee in one's hand, and "From Wal-Mart" while holding up a pen seem like cases where the feature in question can be applied directly to that object without any obvious need to have linguistic material intervene. But in most other cases, the missing linguistic material matters, and this forces the hearer to react to the sub-sentential material much like she would if trying to work out a metaphor or a particularized conversational implicature. ${ }^{7}$ Consider an utterance of a general to his troops, as they hear shelling off in the distance by the shore, "To the beachhead[?]"

${ }^{7}$ This may not always happen, especially if the sub-sentence is one that is frequently used in a particular relationship or in a fine-grained linguistic community (e.g. between spouses or family (father to daughter: "Both hands"), among roommates or colleagues ("To Dave's")). In fact, in such cases where they are used frequently, they seem to approach examples of conventional implicatures or something like shorthand. 
Or as crowds gathering before the football game watch a BBQ truck roll past them and utter "To the stadium?". Even if Stainton is right and some elements of the context are made manifest or salient enough for the communicators to get to the right proposition without the intervention of any additional linguistic material, these sorts of utterances are confusing in even deeper ways than non-literal speech typically is. One needs to work out whether the general is asking about the location of the bombing, or giving a hesitant order to go there, or a description of where the enemy troops will soon be (so we had better not be there); or whether the football fans are suggesting where the truck should go if it wants good business, or where it is going, or where they should go to order from it, etcetera.

It should be clear that I view these cases as degenerate speech acts, but even if they were full-fledged in the requisite sense, this sub-sentential speech places substantial burdens on the audience that would not be present had a full sentence been uttered, and these sorts of cases would be phenomenologically quite similar to nonliteral speech and working out what was implicated. These uses of sub-sentences are hardly exceptional and I think the imprecision they introduce to the communicative scenario points to the burdens the speaker places on the audience by neglecting to utter a full sentence. By my lights, much of sub-sentential speech is like this. The audience has to work out this stuff on their own, with the help of the context, and this is very much like what goes on when processing non-literal or implicated content. ${ }^{8}$

At this point, I could compile examples of actual and fictional examples where these commands and questions failed because they involved sub-sentential speech, as in the case of "By the end of the day" and the examples above; and I could also give plenty of cases where uses of sub-sentences that allegedly assert are substantially like the failed cases of questions and commands in terms of their phenomenological similarity to implicatures and non-literal speech. But, of course, this won't help undermine Stainton's project, since he was never trying to show that all sub-sentential is full-fledged,

${ }^{8}$ As Philip Robbins pointed out to me, a more recent contribution from Stainton and colleagues (de Villiers, Stainton, and Szatmari 2007) raises an avenue for exploring our differences over sub-sentential speech. In that paper, Stainton and colleagues offer evidence that in their population of individuals with Autism Spectrum Disorder, speakers showed some competence with sub-sentential utterances despite having substantially more difficulty with non-literal speech. This sort of evidence offers the possibility of shedding substantial light on these matters, and I will return to this issue in footnote 15 , once I have sketched my alternative account of assertion. 
but rather that some significant portion of it is. However, I want to note that focusing on the best cases of assertion and neglecting the cases where what was uttered was limited enough for the audience to have to struggle to work out the proposition in play unfairly underestimates how generally burdensome sub-sentential speech is on the audience, and hence, the sense in which much of it is degenerate compared to sentential speech. Hence, what I want to do instead of quibbling over cases is to sketch an account of what we do when we assert by uttering a sentence, and how different that is, as a speech act that is directed at an audience, from what we do when we produce a sub-sentence that is directed at an audience. This alternative account should make the case that sub-sentential speech can accomplish much, but that there are good reasons to deem it degenerate in substantial respects.

\subsection{Assertion: An Alternative Account}

What is distinct about sub-sentential speech is that the speaker provides an incomplete structure that serves as an invitation for the audience to complete the sub-sentence in a way that is not constrained by any additional linguistic material. According to Stainton, the sub-sentence is produced, and it is up to the audience to determine what additional material/content to fill in to recover the proposition behind the utterance. It is true that the speaker provides much more, and better, evidence in the sub-sentential case than she would with a mere wink or nudge; she has provided a phrase to help guide the audience to the proposition. But, in the sentential case, the speaker does not place an additional burden on the audience. Many sentences may stand in need of contextual resolution to determine the full proposition that is asserted when it is uttered in a context, but all of the elements that need to be resolved, tweaked, or filled-in are triggered by some element in the syntactic structure, so there is no need to freely add new elements to that structure, when it comes to sentences. The speaker may place additional burdens related to implicatures or non-literal material on the audience, but she provides all of the necessary linguistic material that stands in need of resolution to guide the audience straight to the full proposition that was asserted. ${ }^{9}$ Interpreting a sentence requires the development of

${ }^{9}$ Just how straight this route will be is going to depend on the specifics of the theory involved. Recanati (2004), for example, makes a compelling case that which proposition an utterance of almost any sentence asserts will involve quite a bit of resolution and notes that the consideration of speaker's intentions will be involved 
a given structure; interpreting a sub-sentence requires bringing in a new structure entirely.

This is the sense in which I believe sub-sentential speech fails to really assert. A speaker may get the audience to grasp a proposition by uttering a sub-sentence, but the incomplete guidance is a crucial element that should not be overlooked, and it matters in determining whether sub-sentential utterances are degenerate speech acts, or whether they can be thought to really assert, just like sentential utterances. Stainton is correct in noting that many speakers use linguistic material that does not fully constrain how the audience is supposed to interpret an utterance, but there is a crucial difference between producing a complete linguistic guide to a proposition and providing an incomplete invitation to add to the linguistic material without an overt linguistically mandated constraint on where to stop.

Both types of utterance are common and both can be successful. If the speaker wants to get the audience to the proposition in question, he has two choices: utter a sentence that needs no completion (other than sense specification, reference assignment to indexicals, disambiguation, etc.), or utter something that the audience needs to augment to complete. Following Stainton, we need to get clear about the practical and conversational expectations and burdens that accompany assertions, rather than other types of utterances. From a speech act perspective, the speaker places a substantial burden on the audience by not guiding them with all of the linguistic material that he could have. Successful communication is not guaranteed by using sentences, of course, but the practical consequences of asserting using a sentence are key. What the speaker asserts with a sentential utterance is a direct route to the proposition; what a subsentential utterance provides only gets the audience partly there. The sub-sentential utterance is much more effective than a wink or nudge due to the amount of linguistic material it provides. But, someone who utters a sub-sentence should not become upset if the audience fails to fill in or complete it in the way intended by that speaker, because it was the speaker who chose to provide the incomplete map to the proposition. In the sentential case, the speaker introduces

in this process. I am willing to allow for plenty of resolution and consideration of intentions in this process (e.g., at a minimum, sense specification, reference assignment to indexicals, disambiguation, and similar features), but require that the need for these resolved elements be traceable to slots in logical form. Stainton and Recanati reject that requirement, which is the reason, I will argue, that they will be unable to resist sliding into radical contextualism (a position Recanati seems more comfortable inhabiting than Stainton). 
a linguistic structure into the conversation that is not in need of addition, only resolution. ${ }^{10}$ In the sub-sentential case, the speaker leaves the audience in charge and merely hopes the context can be a sufficient guide to success. ${ }^{11}$

To tie this discussion back into the worries introduced in Section 2, I think that Relevance Theory and the other theories of asserted content that allow for unarticulated constituents of what is asserted face a serious problem in putting a limit upon isolating what is asserted in a context, among all the things that can be communicated in that context. Cappelen and Lepore raise this issue for sentential speech, and I agree that it is a serious concern. But, if my worries about subsentential speech are legitimate, and the speaker is simply inviting the audience to add to the structure in some appropriate way, given the context, I fear that there will be no way of showing when the audience has added too much to the structure, and no way of showing when the audience has added too little to the structure. The old standard is gone -one cannot just complete the structure mandated by the syntax. Instead, Stainton offers the minimal propositional content to constrain what is asserted. But, I think this suggestion lacks sufficient detail to avoid the pitfalls introduced by Cappelen and Lepore.

Stainton offers the following account of asserting as an amendment to the standard Relevance Theoretic account (WT, p. 163):

A speaker $S$ asserts that $p$ only if:

(a) either (i) $p$ results solely from developing the logical form of the expression uttered by $S$, or (ii) $p$ could result merely by developing the logical form of the expression uttered and conjoining it with another manifest logical form of the appropriate semantic type;

${ }^{10}$ An anonymous reviewer pointed out that there are many contexts in which uttering sentences might be quite burdensome. As he or she put it: "We are so apt at exploiting contextual information for communicative purposes, that explicit, fully sentential speech can be overkill." I would certainly not deny this claim - fully sentential speech surely does get in the way in certain contexts, and I am not arguing that all communication needs to be sentential. I agree that sub-sentential communicative acts can be enough to get the job done in some circumstances where sentential acts would be overkill, but they are just not assertions, according to Stainton's own conditions. Stainton is the one who set a higher standard than merely communicating a proposition or getting the job done.

${ }^{11}$ The burdens involved in sub-sentential speech are surely even more substantial when sub-sentences are used to command or question, though I will not extend my analysis to cover them here. 
(b) $p$ is communicated by $S$.

Here is my worry, rephrased. Uses of sub-sentences do not give enough guidance for which logical forms (LF) of the right type can be acceptable additions for conjoining to the LF of the sub-sentence. Flowing from the arguments of Cappelen and Lepore, Relevance Theory's notion of manifestness cannot possibly rule out all sorts of content as being manifest in some context or other. If this is correct, then propositions that are not candidates for what is asserted are going to be the result of combining the LF of the sub-sentence with a LF of some semantic type that is both conjoinable to the sub-sentential LF and consistent with what was communicated. By uttering a subsentence, and communicating a proposition, the speaker is inviting the audience to add some LF of the appropriate semantic type but not further guiding them with linguistic material. If the additional material is a property or object, for example, there will simply be too many available that are manifest enough and consistent enough with what is being communicated.

Stainton believes that the notion of the minimal proposition will save Relevance Theory here, but the main problem with this is that there is not a theoretically neutral way of articulating what counts as minimal in this context. It is a contentious issue whether the minimal contents under discussion capture what is asserted when using sentences, let alone sub-sentences. But, Stainton has two possible sources for these minimal propositions. He could rely upon speaker intuitions about what utterances assert (or, in other terms, roughly, their intuitive truth conditions). In this case, he needs to be able to guarantee that there is a relative consensus about which elements constitute the level of content that is not merely conveyed by the sub-sentential speech. If there are items of a given semantic type that are required to capture the intuitively asserted content, then those minimal aspects should be included in Stainton's proposal, and all non-minimal elements should be excluded, and Stainton should be able to explain which elements are which. Or, Stainton could rely on more metaphysical constraints (i.e. ones that are not dictated by conversational norms or mere speaker intuitions). On this account, what is asserted may be much thinner than speaker intuitions might suggest, since what is minimally asserted is merely whatever components are needed to get the content to the barest proposition possible.

Consider Stainton's example from a conversation between John Dean and Richard Nixon about the publication of a story by the Post, where Dean utters "Typical" (WT, p. 60). Stainton explains 
Here, Dean non-sententially asserts, of the salient event described by Nixon and Haldeman, that it was typical. This is asserted on the proposed account, rather than merely being implicated, because the content of "Typical", being an adjective that must apply to some thing or event, would otherwise remain sub-propositional. (WT, p. 60)

According to Stainton, that this was a typical event for the Post, however, is not asserted, because this "goes well beyond the minimal proposition one gets by finding an appropriate content for 'Typical' to combine with" (WT, p. 60, my emphasis). Hence, for this metaphysical constraints proposal, the only thing to add to an adjective to make it minimally propositional is some relevant event, and nothing else.

This is where things become problematic for Stainton. There are contents that Stainton can easily rule out as legitimately going well beyond what is asserted (he can clearly dismiss several contents as merely conveyed), but there is a large range of contents that can hover around a context that are legitimate contenders for what is asserted (and he seems unable to choose systematically which of these is the asserted content). To give a similar, oft discussed example, it is a matter of significant dispute whether, when uttered, "It's raining" contains an unpronounced constituent in its asserted content about a salient location. ${ }^{12}$ Minimalists who insist that an utterance of this asserts merely that it is raining have been criticized for failing to acknowledge that it intuitively asserts that it is raining at the salient location. Similarly, one might argue that if it is possible to give an asserted content to "Typical", it should be that the publication of the story is typical for the Post. Indeed many people's intuitions point towards this enriched content as being what is asserted, and not merely conveyed by these utterances. Stainton's way of negatively defining what is conveyed, noting that "there are infinitely many propositions that cannot be arrived at merely by developing the Logical Form of that sentence" (WT, p. 162) does a fine job explaining why the fact that a person is not intelligent could only be implicated rather than asserted by "The next Nobel Laureate", and why the information that we should not play tennis could only be implicated but not asserted by "It's raining". But, his notions of assertion and a minimal proposition do not do a sufficient job explaining why, generally, the enriched content that this event is typical for the Post should not count as what is asserted, and it fails to identify which content is asserted.

${ }^{12}$ See Recanati 2004 for a discussion of the myriad perspectives in this debate. 
At this point Stainton could suggest going minimalist in the way Cappelen and Lepore (2005b) suggest for semantic content, in which case he might isolate what is asserted from the intuitive judgments about truth conditions or what is asserted. But, given the Relevance Theoretic framework Stainton endorses, it is up to the speaker to make what he asserts something that he expects the audience can reasonably understand as being asserted with a use of a sentence or sub-sentence. So, whatever LF the speaker expects the audience to augment the sub-sentential LF with can't really diverge from these sorts of intuitions and the relevant expectations towards the audience. These need to be made mutually manifest, after all. One can't define assertion too minimally and expect the audience to work out only those metaphysically required elements and not make the absolutely reasonable, relevant leap to the intuitive content, and then insist, "No! That's not what I asserted. I only implicated or conveyed that this was typical for the Post!" or, additionally, "Just add on this little bit to get to what I asserted - the bare event - not the other stuff the context and I are making mutually manifest - save that for later downstream in the pragmatic processing."

The problem is that there is no natural, principled way to stop all of this expansion of content for sentences, and certainly not for sub-sentences, when uttered. As someone who utters a sub-sentence, you are offering an invitation to complete a sub-propositional element but not giving the audience a reasonable chance to complete it in the desired fashion - there are too many things that could be plausibly filled in for the speaker to affirm or deny that, indeed, that is the proposition that was asserted. It might be acceptable for Cappelen and Lepore to have an error theory about semantic content, ${ }^{13}$ but I do not see how it could be acceptable for Stainton to have one as a theory about asserted content - not if the resources of Relevance Theory are supposed to help fill in the unarticulated aspects of asserted content. What is asserted must be something in line with judgments about what is intuitively asserted, if the speaker is supposed to have expectations that the audience will be able to fill in whatever aspects of asserted content are present. As Stainton explains,

I insist that the intentions a speaker can have are importantly constrained by her reasonable expectations about what the hearer can figure out $[\ldots]$. Thus it is that what the hearer can figure out (something

${ }^{13}$ For example, where speakers' judgments about content diverge from the semanticists' judgments. 
epistemic) ends up constraining what a speaker can intend — which, in turn, is part of the metaphysical determinants of utterance content. (WT, p. 224)

But, if what is intuitively asserted is only minimally constrained by what is linguistically mandated, and instead is only constrained by whatever can be made salient or manifest in a context, then there is no way to limit what can be part of what is asserted.

Relevance Theory has a nice system for explaining how many different ways propositions can be made relevant or manifest in a situation, and how few of these ways involve something like bare encoding and decoding. However, Relevance Theorists have a hard time isolating a genuine role for assertion that does not slide towards what is merely communicated (when it comes to sentential speech). And, since there is a huge difference between what can be made manifest when uttering a sub-sentence and what can be made manifest when uttering a sentence, in that one has so much more control over what one is making manifest with a full sentence, it is not at all clear that one can have reasonable expectations that the audience can work out what is salient given the minimal linguistic guidance of a sub-sentence. Perhaps Stainton has some other resources for getting the level of asserted content just right, but it looks like it is either going to be far too minimal to offer consistent expectations about the ability of the audience to work just that element out, and not the other elements, or far too broad to be contrasted with what is merely conveyed.

Stainton and Relevance Theory sometimes describe utterance interpretation as a "massive interaction effect" (WT, p. 228), and this is what I find worrisome. I do not see how what is asserted avoids becoming lost in these massive interactions, especially once one ceases to require that the elements of asserted content must come from developing the LF of the utterance. As I noted in Section 2, Stainton may be right about sub-sentential speech, and Relevance Theory may end up being the best theory about utterance interpretation, but if this happens, I think the distinction between what is asserted and the rest of the content evaporates. Since this distinction is critical to studying meaning, I think that the range of theories that tie all asserted content to what is developed from pronounced or unpronounced elements in sentential LFs are preferable to what Stainton proposes, at least without more being said about how he aims to 
solve the puzzle he outlines. ${ }^{14}$ Briefly, in the "It's raining" example above, such theories claim that utterances of that sentence assert the intuitive content that it is raining in the relevant location, $\mathrm{L}$, and justify the presence of this unpronounced material as part of what is asserted by offering syntactic tests that justify the presence of a slot for location in LF despite its phonological absence. These theories have a clear divide between what is asserted (whatever is directly traceable to and developed from LF, pronounced or not) and the rest of what is communicated (whatever is not traceable to LF) and maintain a tight fit with what is intuitively asserted. ${ }^{15}$

${ }^{14}$ For articulations of these theories, see Stanley 2000, King and Stanley 2005, and Thompson 2004, and 2007.

${ }^{15}$ As I noted in footnote 8, Stainton and colleagues have given what they describe as an existence proof that at least some speakers with Autism Spectrum Disorder (ASD) have enough pragmatic competence to deal with what utterances assert (i.e. the pragmatic determinants of what is said/asserted), including some competence with some sub-sentential utterances, despite lacking the pragmatic competence to deal with non-literal utterances (e.g. implicatures or what is merely conveyed). The upshot of their results is that it seems pragmatically easier to deal with sub-sentential speech than non-literal content. Hence, my claims about how burdensome subsentential speech is may be called into doubt.

This data is fascinating and I believe that further analyses of these sorts of abilities will certainly help us come to better understand the nature of sub-sentential speech. Briefly, however, I would raise the following concerns:

(1) Do these speakers treat these utterances as assertions, in both producing and comprehending them (e.g. do they treat them with the same legal, conversational, and moral consequences discussed in analyzing condition (iv)?) as opposed to treating them more loosely as mere communicative acts? It is clear that they are communicating with words and phrases in isolation, but should these count as fulfilling (i)-(iv) in the full-fledged sense, and what would count as evidence for this in a population with ASD?

(2) These results will force us to get clearer about what free enrichment and primary pragmatic processing really amount to, and whether things like quantifier domain restriction are examples of free enrichment or not. When looking at the list of linguistic capacities that these speakers do or do not exhibit, one could make the case that the pragmatic abilities they possess might actually be only those that are linguistically mandated/bottom up/triggered by elements in LF/slot filling. After all, if things like sub-sentential speech and quantifier domain restriction really did involve free enrichment or adding new structures to what is already provided, it seems quite puzzling why those with ASD have so much trouble when given other opportunities to freely add contextually relevant material without a linguistic trigger (though the brief sketch offered on p. 313 looks interesting). There is, it seems, at least a prima facie case to be made that all of these capacities are present because the linguistic cue makes them pragmatically tractable for these speakers, such that if there were no linguistic trigger they could not master them, as is the case with the non-literal conveyed content. I agree with Stainton that these speakers with ASD show interest- 


\section{Dividing and Conquering, Again}

The point of the last section was to cast some doubt on whether the sub-sentential speech Stainton discusses is as full-fledged as it needs to be to make his case for the dramatic implications in WT. Stainton's opponents have two sorts of strategies: Deny that a particular use of a sub-sentence is a speech act in the relevant sense; or show that despite appearances, what looked to be uttered in isolation is really sentential after all. My point in this paper has been to stress that we must not allow ourselves to be lured into agreeing with Stainton's proposal by responding to the false choice of: Either the sub-sentential utterance in question is really doing what a sentential utterance would do, only in isolation; or if this isn't the case, the sub-sentential utterance is doing nothing more than a wink, nudge, or kick under the table does. Since I think Stainton makes the case that many examples of sub-sentential speech aren't like these latter acts, it is easy to see sub-sentential speech as being a lot like sentential speech. But, I think that once we recognize the false dichotomy lingering behind his arguments, we can concede that sub-sentences can be used in a variety of ways that nudges can't, but there are still a variety of ways they can't be used in which sentences can.

Given the nature of Stainton's project, if any significant class of sub-sentential speech meets the requirements for full-fledged speech acts, and its members really are sub-sentential, the dramatic implications obtain. In the last section, I offered a speech act diagnosis of what I think sub-sentential speech can do (which is substantial, but falls short of asserting, commanding, questioning, etc.). In this section, reminiscent of Jason Stanley's (2000) divide and conquer strategy, but hopefully avoiding its pitfalls (outlined in WT, chapters 4 and 7), I would like to divide the alleged cases of sub-sentential speech into the following three categories:

(1) Non-propositional, non-communicative sub-sentence uses (e.g., street signs, grocery lists, mutterings)

(2) Degenerate sub-sentence uses (merely communicate $p$ )

ing and unexpected pragmatic abilities, and that they may offer crucial insight into sub-sentential speech, but I don't see how they necessarily help Stainton's analysis of sub-sentential speech over attempts involving unpronounced syntactic structures, e.g. attempts to explain sub-sentential speech via something like syntactic ellipsis, or over attempts to explain quantifier domain restriction via some sort of slot filling as opposed to pure pragmatics or free enrichment. As aforementioned, I think these pragmatic abilities in ASD will help to further these debates. 
(3) Non-degenerate sub-sentence uses (assert $p$ )

Setting aside the first group, which was never the focus of this debate, we can now revisit the cases taken to be full-fledged by Stainton and ask whether, given (2) as an alternative category, we still find a significant set of sub-sentential speech that resists this categorization and demands to be treated as (3). If we can decide that it should be treated as such, I suggest we revisit this class and the matter of whether we can actually handle these as cases of syntactic ellipsis.

Stainton provided a dizzying array of examples to show that no one account of syntactic ellipsis could handle all of the contested cases. But now many of these problematic cases may be seen as degenerate speech acts. With the remaining cases, I propose that we can revisit whether they exhibit any features that could only be introduced within a sentence (as in Peter Ludlow's (2005) account) or whether a move-and-delete proposal might suffice (as in Jason Merchant's (2004) account) to show that the expression has a fully sentential syntax, despite the unpronounced material.

Briefly, to show that there might be some promise to this proposal, recall that I noted above that, by my lights, Stainton's best cases - those where it looks as if uses of sub-sentences are really asserting - are cases where there is an object being talked about which is in (potentially) full view of the interlocutors. "From Columbia" with a bag of coffee in one's hand, and "From Wal-Mart" while holding up a pen seem like cases where the feature in question might be applied directly to that object without any obvious need to have linguistic material intervene. However, these seem like excellent cases that might avoid the pitfalls Stainton raises for Merchant's account of ellipsis. A major flaw in Merchant's proposal is that in discourse-initial uses of sub-sentences, material would have to have been elided without a linguistic controller. Merchant allows for two exceptions where material can be elided without a controller: ${ }_{V P}$ do it] and ${ }_{S}\left[{ }_{N P}\right.$ this/that $]{ }_{I^{\prime}}$ is $\left.\left.\mathrm{t}\right]\right]$. Stainton seemed to allow for these sorts of exceptions, yet warned against allowing Merchant to multiply exceptions beyond these without reason (WT, p. 140). But, for the sub-sentential utterances that seem least degenerate - the best cases of assertion - it seems as though they actually can be handled as cases, even in discourse-initial positions, where $\left[S[N P\right.$ this/that $]\left[I^{\prime}\right.$ is t]] is an excellent candidate for exactly the right sort of thing that would have been elided. Hence, on this proposal the uses of sub-sentences that offer the best chance of really asserting (those of category (3)) would not really be $s u b$-sentential after all. Having 
divided the contested cases in a new manner, it seems warranted to re-examine the cases that seem to resist description as degenerate from the various proposals about syntactic ellipsis.

\section{Conclusion}

In this paper, I have offered some reasons to resist Stainton's treatment of sub-sentential speech. This resistance to his treatment is rooted in worries about its radical implications for the semanticpragmatic distinction and the notion of asserted content. I sketched an alternative account of sub-sentential speech that is grounded in how it differs from sentential speech based on the expectations and burdens it places on the speaker and audience. Because of these unique burdens, it fails to be able to accomplish what sentential speech can, making its instances degenerate speech acts, when compared to many sentential speech acts. By agreeing with Stainton that many cases of sub-sentential speech generally have far more communicative potential than winks or nudges, my account gives subsentential speech its due as a rampant and useful means of communicating and, yet, notes its limitations. In so doing, I believe I have also spotlighted what is unique about what sentential utterances can be used to do, not because they play a special role in logic or because they are the true source of meaningfulness, but because of the direct route they provide towards a proposition.

Though my proposal pales in comparison to the depth and comprehensiveness of WT, I hope to have provided a strategy for dealing with the challenges to semantics and pragmatics that sub-sentential speech suggests. Theorists studying sub-sentential speech can revisit the contested cases of words in isolation with the possibility of acknowledging that sub-sentential speech can do much more than winks or nudges, yet still lack the capacity to assert in the full-fledged way. If there are cases that seem like they are asserting in the full-fledged way, I predict that they are only doing so because they are actually sentential, and should be handled with one of the accounts of syntactic ellipsis. ${ }^{16}$

\section{REFERENCES}

Bach, K., 1994, "Conversational Impliciture", Mind and Language, vol. 9, no. 2, pp. 124-162.

${ }^{16}$ The author wishes to thank Philip Robbins and an anonymous referee for helpful comments on this paper. 
Cappelen, H., and E. Lepore, 2007, "The Myth of Unarticulated Constituents", in O'Rourke and Washington 2007, pp. 199-214.

— , 2005a, "Radical and Moderate Pragmatics: Does Meaning Determine Truth Conditions?", in Szabo 2005, pp. 45-71.

—_ 2005b, Insensitive Semantics: A Defence of Semantic Minimalism and Speech Act Pluralism, Blackwell, Oxford.

Carston, R., 2002, Thoughts and Utterances: The Pragmatics of Explicit Communication, Blackwell, Oxford.

Davidson, D., 1984, "Theories of Meaning and Learnable Languages", in D. Davidson (ed.), Inquiries into Truth and Interpretation, Oxford University Press, Oxford, pp. 3-15.

De Villiers, J., R. Stainton, and P. Szatmari, 2007, "Pragmatic Abilities in Autism Spectrum Disorder: A Case Study in Philosophy and the Empirical", Midwest Studies in Philosophy, vol. 31, pp. 292-317.

Elugardo, R., and R. Stainton (eds.), 2005, Ellipsis and Non-Sentential Speech, Springer, Dordrecht, pp. 95-108.

Fodor, J., and E. Lepore (eds.), 2002, The Compositionality Papers, Oxford University Press, Oxford.

King, J., and J. Stanley, 2005, "Semantics, Pragmatics, and the Role of Semantic Content", in Szabo 2005, pp. 111-164.

Ludlow, P., 2005, “A Note on Alleged Cases of Non-Sentential Assertion", in R. Elugardo and R. Stainton 2005, pp. 95-108.

Merchant, J., 2004, "Fragments and Ellipsis", Linguistics and Philosophy, vol. 27, pp. 661-738.

O'Rourke, M., and C. Washington (eds.), Situating Semantics: Essays on the Philosophy of John Perry, MIT Press, Cambridge, Mass.

Recanati, F., 2004, Literal Meaning: The Very Idea, Cambridge University Press, Cambridge.

Sperber, D., and D. Wilson, 1995, Relevance: Communication and Cognition, 2nd ed., Blackwell, Oxford.

Stainton, R., 2006, Words and Thoughts: Subsentences, Ellipsis and the Philosophy of Language, Oxford Clarendon Press, Oxford.

Stanley, J., 2000, "Context and Logical Form", Linguistics and Philosophy, vol. 23 , pp. 391-434.

Szabo, Z. (ed.), 2005, Semantics versus Pragmatics, Oxford University Press, Oxford.

Thompson, J.R., 2007, "Still Relevant: H.P. Grice’s Legacy in Psycholinguistics and the Philosophy of Language", Teorema, vol. 26, no. 2, pp. 77-109.

- 2004, Contexts, Intentions, and Content: The Role of Intentions in Human Semantic Competence, doctoral dissertation, Washington University in St. Louis.

Received: September 24, 2009; accepted: February 23, 2010. 